\title{
Eligio Ancona y Justo Sierra O’Reilly: una afinidad electiva
}

\author{
Manuel Sol Tlachi \\ Universidad Veracruzana \\ solm@prodigy.net.mx
}

\begin{abstract}
RESUMEN: Después de señalar algunas características de la narrativa de Eligio Ancona, que permiten inscribirlo dentro de la novela del Romanticismo, y la admiración que sentía por la obra histórica y novelística de Justo Sierra O’Reilly, se apunta y precisa, con algunos ejemplos, la presencia del pensamiento y de algunas técnicas narrativas de Sierra O’Reilly (La hija del judio, Los indios de Yucatán, etc.) en novelas de Eligio Ancona como La Cruz y la Espada, El filibustero y El Conde de Peñalva. Impronta que permite considerar a Eligio Ancona no sólo como un discípulo sino como un "alumno" de Justo Sierra O’Reilly, que dejó al margen la novela costumbrista para dedicarse a la novela histórica.
\end{abstract}

Palabras clave: Eligio Ancona; Justo Sierra O’Reilly; novela histórica; novela colonial; literatura comparada.

AвSTRACT: After explaining some characteristics of Eligio Ancona's narrative, which allow us to include him in the novel of Romanticism, as well as pointing out his admiration for the historical works and novels of Justo Sierra O'Reilly, this article makes precisions using some examples of the presence of the ideas and some narrative techniques of Sierra O'Reilly (La hija del judio, Los indios de Yucatán, etc.) in novels by Eligio Ancona such as La Cruz y la Espada, El filibustero and El conde de Peñalva. This proves that it is possible to consider Eligio Ancona not only as a disciple of Justo Sierra O'Reilly but as his "pupil”, one who left aside the costumbrista novel to engage in historical novel.

KeYwords: Eligio Ancona; Justo Sierra O’Reilly; Historical Novel; Colonial Novel; Compared Literature.

FECHA DE RECEPCIÓn: 10 de febrero de 2016.

Fecha de aCeptación: 9 de mayo de 2016.

i examinamos panorámicamente la novela en la península yucateca
durante el siglo xix, junto a narradores como Vicente Calero, Ra-
fael Carvajal, Gerónimo Castillo y Crescencio Carrillo y Ancona, in- 
dudablemente son Justo Sierra O’Reilly (1814-1861) y Eligio Ancona (1836-1893), quienes ocupan un primer lugar en este género.

Independientemente de algunas diferencias, ya sea por los ańos en los que les tocó vivir, por sus lecturas y sobre todo por su personal arte de narrar, existen entre ambos notables semejanzas que nos permiten reconocer la presencia de Justo Sierra en la novela de Eligio Ancona.

La narrativa de Eligio Ancona, cronológicamente, abarca la mayor parte de la segunda mitad del siglo XIX, desde la publicación de La mestiza, en 1861, hasta la redacción de las Memorias de un alférez, esto es, hasta la década de los ochenta. ${ }^{1}$

¿En dónde situarlo?, ¿en qué movimiento literario? o ¿con qué escritores muestra características más afines? Indudablemente pertenece al Romanticismo tanto por sus temas, ideas, actitud de sus personajes y obviamente por su lenguaje o estilo.

En la introducción a La Cruz y la Espada es bastante evidente el culto de Ancona al individualismo y sobre todo a explicar los grandes movimientos de la historia por la acción material o intelectual de un personaje que representa la función de héroe:

Cuando quiere Dios producir uno de esos grandes acontecimientos que cambian aceleradamente la faz de las naciones, como una piedra arrojada en un lago convierte su tranquila superficie en movibles ondas que la agitan por algunos instantes, su poder inmenso sabe suscitar un crecido número de esos hombres extraordinarios, que con su inteligencia superior, su voluntad de hierro y el valor de su brazo, se elevan sobre la multitud que los admira y la conducen fácilmente al término señalado por los designios de la Providencia (Ancona 2014b: 25).

Y entonces cita el cristianismo, el descubrimiento del Nuevo Mundo, la conquista de América, la Revolución francesa, y los asocia, entre otros, a los nombres de Jesús, de Colón, de Hernán Cortés y de los

${ }^{1}$ Sobre la vida y la novela de Eligio Ancona puede verse la "Introducción" a su novela La mestiza (edición, introducción y prólogo de Manuel Sol, Mérida, Sedeculta / Segey..., 2014) o bien las introducciones de Los mártires del Anábuac y El Conde de Peñalva (edición, introducción, bibliohemerografía y prólogo de Manuel Sol, Mérida, Sedeculta / Segey..., 2016). En el proyecto de edición de la narrativa completa de Eligio Ancona, auspiciado por el Gobierno del Estado de Yucatán, se ha publicado también La Cruz y la Espada (Mérida, Sedeculta / Segey..., 2014) y están por aparecer las ediciones de El filibustero y las Memorias de un alférez. 
enciclopedistas franceses. Él aclara que "para hacer menos ostensible" su "audacia" no va a ocuparse en esta novela de Colón, ni de Hernán Cortés o Francisco Pizarro, sino que se limitará a narrar un episodio menos brillante que el descubrimiento del Nuevo Mundo o la conquista del Anáhuac o del Perú; "menos importante que la destrucción del imperio de Moctezuma y del de los Incas"; "pero no menos sembrado de aventuras, de dificultades y de asombrosas peripecias" (28). Y en efecto, narrará en La Cruz y la Espada la conquista de Yucatán, en donde tendrán su lugar correspondiente don Francisco de Montejo, el Mozo y el Sobrino, Tutul Xiu y Nachí Cocom; pero el héroe de la novela será don Alonso de Benavides, un joven andaluz que ha pasado a tierras de América huyendo de la justicia, que mostrará su valentía en la lucha contra los mayas, que se enamorará de Suhuy Kak, hija de Tutul Xiu, batab de Maní, pero que nunca olvidará a doña Beatriz, una muchacha salmantina que, disfrazada de hombre, se trasladará hasta la península de Yucatán en busca de su amado.

Algo semejante ocurre con El filibustero, en donde el protagonista es un pirata, Leonel o Barbillas, cuyo origen se presenta desde el principio como un misterio, y cuya personalidad se caracteriza por la afirmación de su yo frente a la sociedad; y en el transcurso de la acción, ya como Leonel o como Barbillas, se opone una y otra vez a ella, por considerarla inmoral, injusta y arbitraria; y cuando ya no puede luchar más, en una primera ocasión, a mitad de la novela, intenta el suicidio, y finalmente, en el desenlace, cuando todas sus buenas intenciones se estrellan contra las circunstancias, se dispara en la cara para no ser reconocido y así morir heroicamente, pues de esta manera salvará la vida de su amigo Pedro de Cifuentes y conseguirá la felicidad de una familia que finalmente le rendirá culto en el Olimpo.

Lo mismo podríamos decir de otros protagonistas en las novelas de Ancona que sin acudir al suicidio, poseen todas las características de los grandes héroes del Romanticismo, llámense Tizoc, Geliztli (Los mártires del Anábuac), Enrique, Genaro, Aurora (El Conde de Peñalva) o Ramiro de Salazar y María (Memorias de un alférez).

En cuanto a las influencias de otros novelistas en la obra narrativa de Eligio Ancona, también podría pensarse en otros escritores mexicanos o extranjeros. Leticia Algaba en la "Recapitulación" de su tesis doctoral Cuatro novelas históricas mexicanas del siglo XIX. Estudio de historia literaria comparada (2007: 231-235) y en su libro Del pasado al futuro. 
Cuatro novelas históricas mexicanas (2012: 142-144, 192), establece un paralelismo, a propósito del tema de la conquista, entre Vicente Riva Palacio y Eligio Ancona. Pero se trata de simples coincidencias. Sierra O'Reilly en varias ocasiones a lo largo de su obra como escritor y como político alude al olvido en que se encontraba la península respecto al gobierno del centro de la República. Escasa, mínima interrelación hubo en la época colonial y en el siglo xix entre Yucatán y el centro del país, y sin temor a equivocarnos podríamos afirmar que era mucho más viable el contacto con Francia, España o la isla de Cuba.

Ancona, cuando reside en la Ciudad de México, no se presenta como escritor, sino acaso como representante político de Yucatán; no da a conocer sus obras (excepto Los mártires del Anáhuac, que se publica por entregas en la Ciudad de México, en 1870, el mismo año en que se publicó La vuelta de los muertos de Vicente Riva Palacio), ${ }^{2}$ no participa en las veladas literarias, ni asiste a las redacciones de los periódicos; en fin, no hace vida social literaria, aunque desempeña por algún tiempo la secretaría de la Sociedad Mexicana de Geografía y Estadística. Esta discreción explica que no se hayan conocido sus novelas en la capital del país. Ignacio Manuel Altamirano, como Presidente de la República de las letras mexicanas, según lo llamaba El Duque Job (Gutiérrez Nájera: 359) no se ocupa de él una sola vez en sus revistas literarias y si acaso lo cita es como autor de Los mártires del Anábuac (1988a: 232) y más adelante de una Historia de Yucatán (294). De Justo Sierra O’Reilly, Altamirano tiene algunas noticias a través de Justo Sierra Méndez y a través de Francisco Sosa. Pero La hija del judío y Un año en el hospital de San Lázaro no se editan, sino a principios del siglo xx y eso gracias al empeño que puso Justo Sierra Méndez, entonces Ministro de Educación Pública, para que se incluyeran en la "Biblioteca de Autores Mexicanos" de Victoriano Agüeros.

${ }^{2}$ Leticia Algaba en este sentido apunta: "Las simpatías y las diferencias sobre la conquista de México en Los mártires del Anáhuac, de Eligio Ancona y La vuelta de los muertos, de Vicente Riva Palacio se da en varias vertientes. Entre éstas llamó mi atención la heroicidad de los personajes jóvenes, en cuya intervención recae el peso de los últimos combates frente al ejército de Cortés. Riva Palacio y Ancona plantean la pérdida del mundo indígena que parece segar la herencia de los padres otrora guerreros que hicieron del Anáhuac el centro político hegemónico destruido por el conquistador" (2012: 192-193). 
Los asuntos sobre los que escribe Eligio Ancona en cinco de sus seis novelas, son todos yucatecos. Él se muestra muy satisfecho de ocuparse de los temas de su tierra como cuando al final de la Introducción de $\mathrm{La}$ Cruz y la Espada declara que no va a ocuparse de la conquista de México ni de la del Perú, sino de episodios que tienen "para nosotros el glorioso recuerdo de las hazańas de nuestros padres, la grata sombra de los bosques y montañas de nuestra patria y el suavísimo perfume que exhalan las flores del país en que nacimos" (2014b: 28).

El público para el que escribe es el yucateco, según declara en la introducción de la primera edición de El filibustero: "permítasenos — dicepresentar al público yucateco nuestros humildes ensayos, con la esperanza, acaso temeraria, de que los acogerá con la indulgencia que nos ha dispensado hasta aquí" (2010: VIII). Pero la palabra "yucateco" ha sido borrada arbitrariamente de todas las demás ediciones.

No es que no le hubiera gustado que sus obras se leyeran en otros ámbitos o en otras latitudes; ya lo decía Cicerón: Honos alit artes omnesque incendutur ad studia gloria (Cuestiones tusculanas, libro primero, II, 4); sino que quería seguir conservando a su tierra yucateca como algo suyo, propio e íntimo.

Las afinidades electivas de Ancona no se encontraban en el centro del país, ese centro al que poco le importaban los hombres y las obras de la periferia, sino en su mismo Yucatán, en la generación que había elevado hasta un primer plano la obra narrativa, periodística, histórica, y en general, humanística de la península, particularmente de los intelectuales yucatecos que habían colaborado en El Museo Yucateco, en El Registro Yucateco y en El Fénix, revistas o periódicos iniciados por Sierra O'Reilly en 1841, 1845 y 1848 , respectivamente.

Una visión panorámica y al mismo tiempo particular de la obra de Eligio Ancona nos llevaría a señalar y precisar la huella y la influencia de Sierra O'Reilly. En La Cruzy la Espada el propio Ancona, en las notas o en el cuerpo del texto, va haciendo referencia a sus fuentes y en particular a las obras de Sierra O'Reilly. Al final del capítulo V de esta novela, cuando combate la opinión de John Lloyd Stephens acerca de que las grandes ciudades mayas como Uxmal y Chichén Itzá estaban en pie y habitadas durante la época de la conquista, se apoya en los argumentos de Sierra O’Reilly, a quien llama "nuestro inmortal compatriota" (2014b: 92). Lo mismo ocurre cuando niega la conversión de millares de indígenas por obra del padre Jacobo de Testera y otros cuatro franciscanos, en 1535, en 
los alrededores de Champotón, debido a la brusca interrupción de treinta soldados españoles, entre otras razones porque ninguno de los franciscanos sabía la lengua maya. La "buena crítica" — dice Ancona, citando a Sierra O'Reilly - “difícilmente permitirá creer en esa serie de hechos, al menos de la manera en que están presentados por personas que tenían un interés conocido en alterarlos" (149-150). Sobre la opinión acerca de los profetas yucatecos, remite al artículo de Sierra O'Reilly publicado en las primeras páginas del volumen I de El Museo Yucateco [Mérida, 2014, Gobierno del Estado de Yucatán / Sedeculta / Conaculta, 2-8. Edición facsimilar] (195, nota 6). Y cuando un correo le comunica a Tutul Xiu la derrota de las huestes de Nachí Cocom en Tixpehual, un pueblo cercano a Tho (246), transcribe las siguientes líneas, tomadas de Los indios de Yucatán de Sierra O’Reilly: “¿Qué estáis haciendo aquí, oh españoles, cuando vienen contra vosotros más guerreros que pelos tiene una piel de ciervo?” (t. I, 1954: 22), o bien cuando narra la visita de Tutul Xiu al campamento español (Ancona 2014b: 256-257), simplemente copia varios párrafos del capítulo tercero de este mismo libro (t. I, 1954: 2-23), y agrega las siguientes palabras: "El novelista no tiene nada que añadir a las palabras del historiador".

Cuando murió Justo Sierra O'Reilly, el 15 de enero de 1861, Eligio Ancona, que entonces trabajaba en El Constitucional, publicó una breve semblanza, que merece ser trascrita en su totalidad:

Ha fallecido el señor doctor don Justo Sierra. Estas pocas palabras nos parece que bastan para expresar el dolor que debe cubrir hoy al pueblo de Yucatán que tuvo la dicha de verle nacer en su seno. Porque el escritor que, además de esas relevantes cualidades que constituyen a un eminente literato, consagró principalmente su pluma a un objeto de utilidad general, es digno de nuestra gratitud, de nuestra admiración y de vivir eternamente en nuestra memoria. Y el señor don Justo Sierra no perdió nunca de vista el interés general de sus conciudadanos, pues desde su juventud se dedicó a ilustrar al pueblo por medio de la prensa. Comprendió que un hombre, como él, dotado de grandes talentos por la naturaleza, debía emplearlos en enseñar e instruir a sus semejantes, y no hay duda que desempeńó gloriosamente su misión. Ahí están sus escritos: cada uno de ellos es una importante lección, importante para el pueblo, a la vez que un modelo de elegancia y de belleza literaria.

Cábele también a este ilustre ciudadano la gloria de haber dado el primer impulso a la literatura en nuestro país. El Museo Yucateco, así como fue 
la primera obra puramente literaria publicada en Yucatán, es también una de las que más le honran por su belleza, su corrección y su interés histórico.

Don Justo Sierra nos dio pruebas de sus talentos en diversos ramos de la literatura; pero uno de los que le merecieron mayor dedicación fue la historia, y después de haber publicado importantes documentos sobre la del país en los diversos periódicos que sucesivamente redactó, empezó a dar a luz la historia completa de Yucatán. Desgraciadamente, por causas independientes de su voluntad, tuvo que suspender su publicación, y quedamos privados de una obra que hubiera honrado muchísimo a nuestra naciente literatura.

Pero un hombre como el señor Sierra, no es de que aquellos cuya fama pueda encerrarse en los estrechos límites de un Estado. Su nombre es conocido en toda la República como el de un distinguido publicista, pues ha dado a su patria obras de indisputable mérito que honrarían a los países más civilizados del mundo. Y en los últimos meses de su vida ha trabajado incansablemente en la formación del código civil, para la cual fue comisionado por el supremo gobierno de la nación.

El señor Sierra ha ocupado también en diversas épocas los escaños de los congresos y en ellos, como en su vida privada, ha dado siempre muestras de sus virtudes y de su ilustración.

Hay hombres célebres en la historia de todos los pueblos; pero no todos causan en nosotros una misma impresión. Esos grandes guerreros que para alcanzar un fin cualquiera, han derramado ríos de sangre, a pesar de los beneficios que algunas veces han conquistado para su patria y para la humanidad, llevan tras sí no sé qué de doloroso y terrible que amarga mucho la memoria de sus hazańas; pero esos hombres que sin causar ningún mal han consagrado su vida a hacer el bien de los demás con su abnegación, sus luces o su filantropía, viven eternamente en nuestra memoria con el grato y dulce recuerdo de sus virtudes.

El señor don Justo Sierra, para honra de nuestra patria, pertenece a los segundos. Y nosotros que siempre hemos venerado y admirado su nombre, como creemos que le veneran y admiran todos los hijos de este país que tanto le deben, le hemos consagrado en nuestro editorial estos cortos y desalińados renglones (1861: 3-4).

Bastaría este texto para demostrar la admiración que sentía Eligio Ancona por Justo Sierra O’Reilly. Pero Ancona no se limitó a admirarlo, sino a seguir sus pasos como novelista y como historiador.

En su Historia de Yucatán, al trazar un panorama de la cultura en Yucatán durante el siglo XIX, vuelve a insistir en la importancia que tuvieron El Museo Yucateco y El Registro Yucateco y afirma: 
Puede decirse que de estas dos publicaciones arranca el origen de nuestra literatura, porque desde entonces fue cuando empezó a ser cultivada en varios de sus ramos. La historia, la biografía, la lingüística, la novela, la leyenda y la crítica comenzaron a disputar al artículo político y a la poesía lírica, el exclusivismo que hasta entonces habían ejercido en las letras (IV, [1880] 1978: 406).

Más adelante precisa la labor de Sierra O’Reilly como historiador sobre el establecimiento del territorio británico de Belice y muy particular elogio le merece la obra Los indios de Yucatán. Consideraciones históricas sobre la influencia del elemento indigena en la organización social del pais (Campeche: José María Peralta, 1857) que apareció por primera vez en el periódico El Fénix entre 1848 y 1851, y de la que obtuvo información para la redacción de algunas de sus novelas como lo hemos visto a propósito de La Cruz y la Espada. Destaca también su labor de biógrafo en las vidas de los obispos, gobernadores y algunos hombres de artes, ciencias y letras. No podía pasar por alto su labor de novelista en Un año en el hospital de San Lázaro, La hija del judio y algunas leyendas, entre las que habría que mencionar El filibustero y particularmente Los bandos de Valladolid y El secreto del ajusticiado, cuyos protagonistas reaparecerán en su novela homónima El filibustero, aunque en el capítulo I de esta obra, Ancona sólo menciona Los alcaldes de Valladolid del escritor español Antonio García Gutiérrez, drama en verso y prosa publicado en Mérida por la Imprenta de Castillo y Compañía en 1845. Y lo que escribe acerca de este drama como fuente, también podría aplicarse a las llamadas "leyendas" de Sierra O’Reilly que seguramente leyó y pudieron haberle servido como insinuación temática:

Empezamos a escribir cometiendo una profanación.

Nuestra pluma se ve obligada a trazar en esta primera parte el cuadro que ha inspirado a García Gutiérrez su drama Los alcaldes de Valladolid.

En dos palabras daremos nuestra disculpa.

La historia es una fuente pública cuyas aguas apagan la sed del rico y del pobre, del hombre y del niño, del grande y del pequeño. García Gutiérrez se llegó a esa fuente en 1845 y bebió; nosotros nos acercamos a ella en 1864 , tenemos sed y bebemos también.

¿Por qué no?

Esto no arranca una sola hoja a la corona del ilustre poeta español ni saca de su oscuridad al pobre novelista yucateco, que lucha con inmensas 
dificultades para publicar un libro en el estrecho círculo que constituye su teatro. Además de esto, en el pecado llevaremos la penitencia, porque al comparar Los alcaldes de Valladolid con El filibustero, la única esperanza que nos alienta es la de que el ruido de los aplausos prodigados al gran poeta apague el de los silbidos lanzados al audaz novelista.

Por último, el asunto principal del drama y de nuestra novela son enteramente distintos: aquél entra de lleno en la historia, y nosotros no la tocamos más que por incidencia; de manera que, aun a riesgo de que se diga que cometemos una segunda profanación, diremos de ese episodio de la historia del país lo que Dumas dice de Enrique VIII en Catalina Howard: "no es más que un clavo al cual hemos colgado nuestro cuadro" ([1864] 2010: 1-2).

El pasaje es bastante aleccionador, porque nos permite ver cómo Ancona se aproximaba a sus fuentes. No se trataba de una "profanación", sino solamente de un punto de partida, pues aunque el tema y algunos personajes son los mismos, el género, el argumento, la estructura, la caracterización de personajes y el desarrollo de algunos aspectos históricos, eran completamente distintos.

Lo mismo podríamos decir de El filibustero de Sierra O’Reilly y El filibustero de Ancona; o bien, de El Conde de Peñalva.

Don García de Valdés Osorio es un personaje en torno al cual gira la acción de La hija del judio de Sierra O'Reilly y de El Conde de Peñalva de Eligio Ancona.

Independientemente de la semejanza de los temas o de la coincidencia de personajes, el magisterio de Sierra O'Reilly se encuentra en el ejemplo que dio a Ancona y a los escritores jóvenes de escribir novelas históricas; de ir a buscar los temas de la literatura en la historia de Yucatán como lo había proclamado en la "Introducción" de El Registro Yucateco: "Contendrá artículos acerca de la historia antigua del país, noticias curiosas, biografías, leyendas, poesías, y todo cuanto contribuya a hacerlo ameno y útil al mismo tiempo". En El Registro Yucateco, al anunciar la reimpresión de la Historia de Yucatán de Diego López Cogolludo, decía que ésta era "una mina inagotable, que pueden explotar el poeta y el romancero, el historiador y el filósofo" (El Registro Yucateco, III, 243-244). ${ }^{3}$ Y a ella acudió Eligio Ancona no sólo para la redacción

${ }^{3}$ En El Museo Yucateco Sierra O'Reilly había rescatado y difundido varios textos sobre la historia, la literatura y la arqueología de Yucatán, y algunos fragmentos 
del primer y gran parte del segundo tomo de su Historia de Yucatán, sino también para la redacción de sus novelas históricas. Muchas son las ocasiones en las que Ancona cita o remite a López Cogolludo, ya sea en nota o en el cuerpo del texto (véase, por ejemplo, en El Conde de Peñalva, la descripción que hace del recorrido de Enrique, el hermano de la protagonista, entre Mérida y Campeche, y en particular la narración de los milagros de "Nuestra Señora de la Laguna" en el pueblo de Hampolol: Ancona [1879] 2016b: 73-86; López Cogolludo: III, 397-401).

Pero, independientemente de la sugerencia de dedicarse a la escritura de novelas sobre la historia de Yucatán, Sierra O’Reilly dio el ejemplo de la composición de una novela romántica en La hija del judio, en la que partiendo de la información que le proporcionaban los Manuscritos inéditos del P. Nicolás de Lara (que también utilizó Ancona en varios episodios de sus novelas), e innumerables pasajes de la Historia de Yucatán de Diego López Cogolludo, compuso un relato de suspenso que se sustenta en dos anécdotas históricas: el asesinato del conde de Peñalva y la misteriosa cita que se le dio al gobernador Fr. José Campero la noche del 29 de diciembre de 1662. He aquí cómo explica en parte Sierra O' Reilly la génesis de la trama de La hija del judio:

Aunque parezca algo impertinente el que se me vea detenido en estas fruslerías, ocupando tontamente el tiempo de los que tienen la bondad de leerme con hablarles de mí mismo, no quiero malograr esta oportunidad, aun a riesgo de parecer realmente importuno, de hacer una observación sobre La hija del judío, siquiera porque la concebí durante mi residencia en los Estados Unidos y sus primeras páginas tienen alguna conexión con mis impresiones de viaje. La observación de que ya he hablado es ésta: El suceso trágico de la muerte del conde de Peñalva no me parecía, solo y aislado, muy propio para el argumento de un romance o novela. Yo había llegado a persuadirme, en vista de algunos relatos mal compaginados que he leído detenidamente, que la cita misteriosa que se dio para la catedral al gobernador Campero y su conversación con un alma, tenían cierta conexión con el tenebroso asesinato del conde. Se recordará también que el P. Lara, o el autor del M. S. que publiqué en mi periódico literario El Museo Yucateco, al hablar de ese raro incidente, añade que corrían voces de que los jesuitas y el obispo se habían puesto de

de la Historia de Yucatán de López Cogolludo bajo el título de "Antiguallas de Yucatán”. 
acuerdo para una añagaza, de que fue víctima el gobernador Campero. Pues bien, pasando por cualquier anacronismo, me determiné ligar un suceso con el otro, revistiéndolos de una serie de particulares circunstancias, de que yo tenía una buena provisión en mis notas y apuntes históricos, formando un conjunto monstruoso si se quiere, pero muy propio para despertar la curiosidad sobre unos hechos ignorados del todo, o profundamente olvidados por la generalidad. Casi nada de lo que he referido en La hija del judio ha sido inventado por mí: la combinación, la fábula es lo único que me pertenece; y aunque éste sea el mayor vicio de que adolezca, no he de pretender lavarme las manos para evitar la crítica. Quod scripsi, scripsi, y no puedo testarlo (2012: 416).

En La hija del judio, el narrador, siguiendo la historia de López Cogolludo mediante diversas anécdotas, explicará las causas de la escasez de maíz, el hambre y la pobreza por las que atravesaba la península durante el gobierno del conde de Peńalva; y el padre Noriega, en la Segunda Parte de la novela, siguiendo particularmente el relato de P. Nicolás de Lara en sus Manuscritos inéditos, le contará a don Luis de Zubiaur, el prometido de la hija del judío, la administración de la península en la época del conde Peñalva, encaminada a la explotación de sus habitantes, tanto españoles como indios; su conducta altanera y voluntariosa que hace agravar el enfrentamiento con los ayuntamientos de Mérida, Campeche y Valladolid; su vida licenciosa que alcanza su clímax cuando intenta seducir a doña María Altagracia de Gorozica —esposa de don Felipe Álvarez de Monsreal, a quien el conde había denunciado como judío y recluido en las cárceles de la Inquisición-, la que se convierte finalmente en la nueva Judit vengadora cuando asesina al conde en su propio palacio.

Eligio Ancona inicia El Conde de Peñalva haciendo una breve semblanza del conde de Peñalva, en la que se destaca su holgazanería, avaricia y su vida licenciosa, y cuando Enrique, un joven estudiante en el convento de San Francisco, encabeza un motín contra los oficiales del conde en los momentos en que éstos se niegan a venderle a la gente del pueblo el maíz a un precio razonable. Pero Enrique en vez de ser castigado por su oposición a las disposiciones del conde, es premiado con el puesto de alférez real en el puerto de Campeche, debido a que el conde se había enterado por su secretario Escobedo que era hijo de dońa Juana y hermano de Aurora, la joven en la que había puesto sus miras. Cuando Enrique se entera de los motivos de su nombramiento 
monta en cólera y regresa a Mérida para renunciar a su puesto y retar al conde, pero justamente cuando está a punto de entrar a palacio, se encuentra con Genaro, el novio de Aurora, y ambos retan al conde. En La hija del judío es don Felipe Álvarez de Monsreal quien en compañía de Alonso de la Cerda, el futuro padre adoptivo de la hija del judío, retará al conde cuando se entera de que éste corteja a doña María Altagracia de Gorozica, su prometida.

El hecho, si no histórico, era parte de la leyenda del conde de Penalva. Joaquín Lanz Trueba, apoyándose sobre todo en lo que Juan Francisco Molina Solís asienta sobre el conde en su Historia de Yucatán (1910: II, 183-227), duda de la veracidad de este acontecimiento. Supone que estos dos retadores pudieron ser Pedro Díaz del Valle y Francisco Crespo de Morales, depuestos por el conde: el primero de su cargo de Secretario y Escribano Mayor de Gobernación y Guerra, y el segundo, de su cargo de Defensor de los Indios. Pero concluye que nada puede probarse (Lanz Trueba: 175-177). Y precisamente porque no se sabía el nombre de los retadores, y este acontecimiento se encontraba en el misterio, como tantos otros en torno a la vida del conde, es que Sierra O'Reilly pudo atribuirlo a don Felipe Álvarez de Monsreal y a don Alonso de la Cerda, y Eligio Ancona a Enrique y a Genaro.

Sobre las circunstancias misteriosas en las que se da la muerte del conde de Peñalva, según lo narra Sierra O’Reilly y Eligio Ancona, también hay muchas similitudes, debido a que ambos abrevaron en la misma fuente, y Ancona tenía también como antecedente inmediato a $\mathrm{La}$ hija del judio.

Sierra O’Reilly, según hemos visto, la atribuye a doña María Altagracia de Gorozica, la persona más agraviada, cuando ésta acepta visitar al conde en su palacio la noche del $1^{\circ}$ de agosto de 1652.

Eligio Ancona reserva el asesinato a dońa Juana, la madre de Enrique y Aurora, que al suponer al conde culpable de la muerte de sus hijos, se dirige a palacio, y tras algunos titubeos causados por la oscuridad, la tempestad y su estado de ánimo, termina por asestar dos puñaladas en el pecho del conde. El capítulo se titula "El monstruo venga sus hijos". Pero el narrador había llamado indistintamente en varias partes de su narración "monstruo" a dońa Juana y al mismo conde. Calificativo, aplicado a este último, quizá inspirado en un documento procedente de los archivos del Ayuntamiento de Mérida: 
Fue este gobernador el azote de la provincia que desoló y destruyó con sus repartimientos, causando en ella, con la hambre que introdujo, más ruinas y muertes en toda ella que las plagas de langostas que en otro tiempo había sufrido. [...] Con el pretexto de escasez de maíz, nombró comisionados, con la denominación de jueces españoles, para que fuesen por todos los pueblos de indios a registrar el maíz que tenían, dejándoles solamente el necesario para el sustento de sus familias, y quitándoles lo restante, a pretexto de asegurarlo para alimentar a los demás. [...] Viendo que la inmediata cosecha se presentaba abundante, para no perder su monopolio mandó que ningún indio pudiese vender maíz a nadie hasta que averiguase la cosecha de aquel año para proveer a todos. Con estas artes infernales, el maíz, que antes se vendía a seis reales carga, subió muy pronto a doce pesos fuertes en 1651 , y a seis pesos en 1652, a pesar de la abundancia de las cosechas, con lo que, una hambre espantosa, no vista hasta entonces, colmando las arcas de este monstruo abominable, produjo en la provincia la horrorosa mortandad que la despobló casi del todo (ápud Molina Solís 1910: II, 220-221).

El P. Nicolás de Lara en sus Manuscritos inéditos había dicho:

1649.- El conde de Peñalva D. García de Valdez Osorio, tomó posesión a 19 de octubre, y gobernó dos ańos, nueve meses y once días hasta $10[s i c]$ de agosto de 652 , en que le hallaron muerto a puñaladas entre nueve y diez de la noche en su dormitorio, no habiendo a quién atribuir el homicidio, porque tenía a toda la provincia ofendida, y los pobres se quejaban más por haber estancado los granos dos años, de que sucedió la más calamitosa hambre que hasta aquellos tiempos se había visto. Moríanse por las calles, caminos y montes, los indios, chinos, mulatos, mestizos y españoles. Fue hombre ríspido, tirano y avaro, y cuando murió se le hallaron en plata sellada, labrada y alhajas de oro, cerca de sesenta mil pesos, y en Méjico como cuarenta mil del valor de sus repartimientos. Fue el primero que tasó veinte y cinco mantas por mil pesos de regalía sobre los que pretendían encomienda. La fatal desventura de su tragedia no la he podido conformar por más que la he tirado a ceńir a lo mejor de las conjeturas, porque se cuenta muy varia, aun en las mismas declaraciones hay claudicación. Lo único que se trasluce más creíble es que aquella noche entró una mujer en su cuarto con pretexto de pedir justicia dejando a su marido que la acompańaba a la puerta, siendo persona no desconocida de la familia, que estaba retirada holgándose abajo: ésta se volvió a salir y a cabo de más de media hora fue un paje a saber si el conde quería cenar, y lo halló muerto: hay quien diga que la mujer que 
entró era un caballero vestido en aquel traje, lo cierto es que nada pudo averiguarse (1841: I, 145-146).

Independientemente de la invitación a escribir sobre la historia de Yucatán y dar el ejemplo de cómo se escribe una novela histórica, en La hija del judio de Sierra O'Reilly es frecuente un constante desplazamiento entre el pasado y el presente con el objeto de comparar ambas épocas en lo que respecta al paisaje, las costumbres y las circunstancias históricas. Y aunque ésta sea una característica de una gran parte de la novela histórica romántica, lo que le da mayor similitud entre Sierra O’Reilly y Ancona es que escriben sobre los mismos temas, la acción de sus novelas transcurre en los mismo lugares y comparten la misma ideología, pues ambos eran de ideas liberales.

Sierra O’Reilly inicia La hija del judío dirigiéndose a sus contemporáneos cuando dice:

Aquéllos de mis lectores que, como yo, conozcan detalladamente la ciudad de Mérida, recordarán sin duda el aspecto fúnebre y ruinoso de cierta casa que allá en tiempos remotos perteneció a una familia ilustre. Acompáńenme hasta el ángulo noroeste de la Plaza Mayor, avancen una, dos cuadras hacia el norte y deténganse al terminar esta dirección. En la esquina occidental de esta segunda cuadra existen las ruinas de la casa referida. ¿ No es verdad que su apariencia es melancólica, y más cuando se reflexiona en el contraste que presentan unas ruinas en medio de un pueblo animado? ¿No es verdad que ese montón de escombros en el corazón mismo de una bella capital, es en alguna manera repugnante?

A mediados del siglo XviI, en lugar de esos desplomados techos y derruidas paredes, había una casa, si no espléndida, a lo menos de muy decente apariencia (101-102).

Y de aquí nos traslada hasta mediados del siglo Xvir para contarnos quiénes eran sus habitantes, cómo eran los muebles de la casa y qué costumbres tenían. Contrasta la austeridad de una casa colonial de clase media en Mérida con el refinamiento de muebles que nos envía la "industria francesa” y las costumbres en el comer de aquella época con las modernas.

Este contraste le sirve también para ir proporcionando datos históricos, pero sobre todo para hacer comparaciones entre la situación material, social y política entre ambas épocas. Inútil resulta decir que sus comentarios políticos están hechos desde una ideología del siglo XIX. 
Significativa en este aspecto es la breve historia que nos proporciona de cada uno de los cambios que sufrió durante la época colonial hasta mediados del siglo xix la Casa de Gobierno, que entonces se llamaba el Real Palacio. Brevemente se nos enumeran y describen cada una de las transformaciones que en su exterior experimentó este edificio llevados a cabo por don Carlos de Luna y Arellano, don Antonio de Figueroa, el Marqués de Santo Floro (don Diego Zapata Cárdenas), don Juan José Vértiz y Ontañón y don Benito Pérez Valdelomar (423-435).

Al comparar la función de las Casas Consistoriales de la Colonia en cuanto al poder absoluto del que disponían y los Ayuntamientos de su época, dice que no hay gran diferencia, y que esto será siempre un obstáculo para que prospere un verdadero republicanismo:

Del poder absoluto e ilimitado de la época colonial, hemos pasado al gobierno más amplio y liberal, que reconocen las teorías de los publicistas modernos; pero ese cambio ha de ser y será, por fuerza, nominal, mientras se le haga consistir solamente en fórmulas y palabras muy sonoras, cuando se pronuncian en la tribuna, y vacías cuando se trata de aplicarlas (732).

Eligio Ancona, por su parte, al iniciar el capítulo III de la Segunda Parte de El filibustero, establece una serie de comparaciones entre las costumbres de la época colonial y las de sus contemporáneos, respecto a la puntualidad, la venta de empleos en los cabildos, la indiferencia a representar cargos públicos cuando no tienen paga o el hecho de que los antepasados se conformaban con un puesto menor en el ayuntamiento y ahora muchos apenas creen recompensados sus méritos cuando se les ofrece una cartera de ministro o una banda de general. ";Oh tempora! ¡Oh mores!”([1864] 2010: 201). Y más adelante, respecto a las personas que se encontraban en los cargos públicos, comenta que la sociedad antigua buscaba la prudencia, la sabiduría y la reflexión, propia de los ancianos, y que la sociedad actual "ha adoptado el extremo contrario y generalmente se apoya en la juventud" (202).

Pero en donde parece aventajar a Sierra O'Reilly es cuando hace crítica social describiendo situaciones en el pasado y que se repiten idénticamente en el presente, como es el caso de la explotación del indio en las encomiendas y ahora en las haciendas henequeneras; la venalidad de los Gobernadores y Capitanes Generales en la Colonia y ahora en los 
hombres de los más altos puestos públicos; la complicidad tanto en el pasado como en el presente entre las autoridades y los delincuentes, etc. Por eso asienta al iniciar El filibustero en comparación con lo narrado en La Cruz y la Espada que entre una y otra novela median ciento sesenta ańos, y que aunque el escenario es el mismo, la escena es distinta, pero no porque hayan cambiado los móviles de la explotación y de hacer riqueza, pues al conquistador ha sucedido el encomendero que "encerrado en sus inmensas posesiones, como un barón feudal de la Edad Media, sólo cuida de explotar al miserable aborigen"; al clérigo, a veces un auténtico misionero de la doctrina de Jesús, "ha sucedido el fraile o el cura convertido en publicano, que gasta la mayor parte de su tiempo en inspeccionar el cobro de sus rentas y en aumentar sus matrículas"; a los aventureros, "han sucedido los gobernadores y capitanes generales, que con muy honrosas excepciones sólo se dedican a sacar de su posición toda la utilidad posible"; al aborigen, que luchaba por conservar su independencia, "ha sucedido el indio pupilo, hipócrita y disimulado, que sufre su yugo con aparente conformidad. [...] Pero cada azote, cada humillación, cada rapiña arranca de sus ojos una lágrima sorda, que derrama silenciosamente por la noche en su reducido tugurio o en la soledad de sus bosques" ([1864] 2010: V-VIII). Y de aquí a la guerra social o de castas sólo había un paso.

Justo Sierra O’Reilly murió en los primeros días de 1861; Eligio Ancona publicó su primera novela, La mestiza, a finales de 1861. Moría el maestro, o como se ha dicho "el patriarca de la literatura yucateca", pero nacía en las letras mexicanas no simplemente un discípulo, sino un alumno, que dejó al margen la novela costumbrista (La mestiza) y se dedicó de aquí en adelante a la novela histórica.

\section{BibLIOHEMEROGRAFÍA DIRECTA}

Ancona, Eligio. "La redacción” [Semblanza de Justo Sierra O’Reilly a propósito de su fallecimiento], en El Constitucional, Mérida (16 de enero de 1861), núm. 355, pp. 3-4.

Ancona, Eligio. Memorias de un alférez. Novela histórica, 2 vols. Introducción de José María Pino Suárez. Mérida: Imprenta de "El Peninsular", 1904 [Introducción de José María Pino Suárez, 2 vols. Mérida: Editorial Yucatanense]. 
Ancona, Eligio. Historia de Yucatán desde la época más remota hasta nuestros dias, 4 vols., en 5 tomos. Mérida: Ediciones de la Universidad de Yucatán, 1978 [4 vols. Mérida: Imprenta de Manuel Heredia Argüelles, 1878-1880].

Ancona, Eligio. El flibustero. Novela histórica. "Prólogo" de Celia Rosado Avilés. Mérida: Gobierno del Estado de Yucatán / Instituto de Cultura de Yucatán, 2010 [Mérida: Imprenta a cargo de Leonardo Cervera, 1864].

Ancona, Eligio. La mestiza. Novela original. Edición, introducción y prólogo de Manuel Sol. Mérida: Sedeculta, 2014a [Mérida: Imprenta de la Sociedad Tipográfica, 1861].

Ancona, Eligio. La Cruz y la Espada. Novela histórica. Edición y prólogo de Manuel Sol. Mérida: Sedeculta, 2014b [Mérida: Leonardo Cervera, $1864]$.

Ancona, Eligio. Los mártires del Anáhuac. Novela histórica. Edición, introducción, bibliohemerografía y prólogo de Manuel Sol. Mérida: Sedeculta / Secretaría de Educación de Yucatán, 2016a [México: Imprenta de José Batiza, 1870; México: Conaculta / Planeta De Agostini, 2004].

Ancona, Eligio. El Conde de Peñalva. Novela histórica. Edición, introducción, bibliohemerografía y prólogo de Manuel Sol. Mérida: Sedeculta / Secretaría de Educación de Yucatán, 2016b [Mérida: Imprenta de Manuel Heredia Argüelles, 1879].

\section{BiBLIOHEMEROGRAFÍA INDIRECTA}

Algaba Martínez, Leticia. "De la periferia al centro: Los mártires del Anáhuac de Eligio Ancona”, en Rafael Olea Franco (ed.). Literatura mexicana del otro fin de siglo. México: El Colegio de México, 2001: 239-249.

Algaba Martínez, Leticia. "Por los umbrales de la novela histórica”, en Belén Clark de Lara y Elisa Speckman (eds.). La república de las letras. Asomos a la cultura escrita del México decimonónico, t. I. México: Universidad Nacional Autónoma de México, Coordinación de Humanidades. Programa Editorial, 2005: 287-302 (Ida y regreso al Siglo XIX).

Algaba Martínez, Leticia. Cuatro novelas históricas mexicanas del siglo XIX. Estudio de historia literaria comparada. Tesis de doctorado en Letras. México: Universidad Nacional Autónoma de México, 2007.

Algaba Martínez, Leticia. Del pasado al futuro. Cuatro novelas históricas mexicanas. México: Universidad Autónoma Metropolitana, 2012.

Altamirano, Ignacio Manuel. Obras completas, XII. Escritos de literatura y arte, tomo 1. Selección y notas de José Luis Martínez. México: Secretaría de Educación Pública, 1988a. 
Altamirano, Ignacio Manuel. Obras completas, XIII. Escritos de literatura y arte, tomo 2. Selección y notas de José Luis Martínez. México: Secretaría de Educación Pública, 1988b.

Altamirano, Ignacio Manuel. Obras completas, XIV. Escritos de literatura y arte, tomo 3. Selección y notas de José Luis Martínez. México: Consejo Nacional para la Cultura y las Artes, 1989.

Barrera Osorio, Abelardo. "Vida, pasión y muerte del Conde de Peñalva" y "El misterioso asesinato de D. Lucas de Gálvez", en La Mérida colonial. Mérida: Talleres Gráficos del Sudeste, 1961: 77-80, 113-123.

Leal, Antonio. "Eligio Ancona", "Prólogo" a Los mártires del Anáhuac, "Prólogo" a El filibustero, "Prólogo" a Memorias de un alférez, en La novela del México colonial, t. I. México: Aguilar, 1964: 401-402, 619-620, 795796.

Esquivel Pren, José. “Eligio Ancona Castillo”, en Historia de la literatura en Yucatán, t. VIII. México: Ediciones de la Universidad de Yucatán, 1975: 119-173.

Esquivel Pren, José. “Eligio Ancona”, en Enciclopedia Yucatanense, tomo V. México: Edición Oficial del Gobierno de Yucatán, 1977: 637-643.

Gutiérrez Nájera, Manuel. Obras I. Crítica literaria. Ideas y temas literarios. Literatura mexicana. Investigación y recopilación de Erwin K. Mapes. Edición y notas de Ernesto Mejía Sánchez. Introducción de Porfirio Martínez Peńaloza. México: Universidad Nacional Autónoma de México, 1959.

Lanz Trueba, Joaquín. “¿El reto al conde de Peñalva, es cierto?”, en Estudios Históricos. Mérida: Talleres Gráficos del Sudeste, 1938: 175-177.

LARA, José Nicolás DE. "Manuscritos inéditos”, en El Museo Yucateco, I. Campeche: Impreso por José María Peralta, 1841: 57-60, 101-103, 135-147, 182-185, 225-238, 262-[264], 296-306, 342-348, 378-384, 425-436.

López Cogolludo, Diego. Historia de Yucatán, 3 vols. Campeche: Gobierno Constitucional del Estado, 1955.

Menéndez Rodríguez, Hernán R. "El liberalismo en Yucatán: de la Reforma al Imperio", en Unicornio. Suplemento de Por esto! Mérida, núm. 109 (25 de abril de 1993): 3-11.

Menéndez Rodríguez, Hernán R. Iglesia y poder. Proyectos sociales, alianzas politicas y económicas en Yucatán (1857-1917). México: Nuestra América / Consejo Nacional para la Cultura y las Artes, 1995.

Molina Solís, Juan Francisco. El conde de Peñalva, Gobernador y Comandante General de la Península de Yucatán. Estudio histórico. Mérida: s.p.i., 1889.

Molina Solís, Juan Francisco. Historia de Yucatán durante la dominación española, t. I. Mérida: Imprenta de la Lotería del Estado, 1904. 
Molina Solís, Juan Francisco. Historia de Yucatán durante la dominación española, t. II. Mérida: Imprenta de la Lotería del Estado, 1910.

Molina Solís, Juan Francisco. "Las sociedades literarias en Yucatán, desde 1810 a 1870", en Salón Literario. Mérida, año I, núm. 3 (31 de marzo de 1898): 81-97.

Peniche Barrera, Roldán y Gaspar Gómez Chacón. “Ancona, Eligio”, en Diccionario de escritores de Yucatán. Mérida: CEPSA Editorial, 2003.

Rosado Lugo, Diana María Magnolia. "El liberalismo en la novela histórica yucateca del siglo XIx", en Unicornio. Suplemento cultural de Por Esto! Mérida, núm. 66 (28 de junio de 1992): 3-7.

Sierra O'Reilly, Justo. Los indios de Yucatán. Consideraciones sobre la influencia del elemento indígena en la organización social del pais. 2 vols. Campeche: Editor Carlos R. Menéndez. Mérida: Tipografía Yucateca, 1954-1957 [Campeche: José María Peralta, 1857].

Sierra O'Reilly, Justo. El filibustero y otras historias de piratas, caballeros y nobles damas. Recopilación, edición e introducción de Manuel Sol. México: Universidad Veracruzana, 2006.

Sierra O’Reilly, Justo. La hija del judio, 2 vols. Edición crítica, introducción y notas de Manuel Sol. México: Universidad Veracruzana, 2008.

Sierra O'Reilly, Justo. Impresiones de un viaje a los Estados Unidos de América y al Canadá. Edición y estudio preliminar de Manuel Sol. México: Universidad Nacional Autónoma de México, 2012. 